Check for updates

Cite this: RSC Adv., 2018, 8, 39635

Received 19th September 2018 Accepted 21st November 2018

DOI: 10.1039/c8ra07799a

rsc.li/rsc-advances

\section{Detection of cadmium in soils using laser-induced breakdown spectroscopy combined with spatial confinement and resin enrichment}

\author{
Xinglan Fu, $\uparrow^{\mathrm{ab}}$ Guanglin $\mathrm{Li}, \uparrow^{\mathrm{a}}$ Hongwu $\operatorname{Tian}^{\mathrm{b}}$ and Daming Dong (D) *b
}

\section{Introduction}

Soil is an important part of the ecological environment, and is a major resource contributing to human survival and development. ${ }^{1}$ Along with urbanization, industrialization, mineral resource development and use of metal smelting, the application of sewage irrigation and fertilizers as well as other human activities have contributed a variety of heavy metal pollutants through various channels to the soil. This has caused increasingly serious heavy metal pollution of soils. ${ }^{2}$ Any introduction of this heavy metal pollution into the human body through the food chain will cause harm to human health. $^{3-6}$ Therefore, an effective detection of heavy metal content in soils and the control of excessive heavy metal source emissions are both important means to improve the safety of agricultural products and food.

Conventional analytical techniques for soils involve inductively coupled plasma atomic emission spectrometry (ICP-OES), inductively coupled plasma mass spectrometry (ICP-MS), laser ablation-inductively coupled plasma-mass spectrometry (LAICP-MS), high performance liquid chromatography (HPLC),

${ }^{a}$ College of Engineering \& Technology, Southwest University, 216 Tiansheng Road, Beibei, Chongqing, 400716, PR China

${ }^{b}$ Beijing Key Laboratory of Digital Plant, National Engineering Research Center for Information Technology in Agriculture, Beijing Academy of Agriculture and Forestry Sciences, Beijing 100097, China. E-mail: damingdong@hotmail.com; dongdm@ nercita.org.cn

$\dagger$ These authors contribute equally to the paper. atomic fluorescence spectrometry (AFS), atomic absorption spectroscopy (AAS) and X-ray fluorescence analysis. ${ }^{7-9}$ These methods are widely used in soil for microelement analysis because of their high sensitivity and repeatability. ${ }^{10}$ However, these methods require time-consuming sample preparation and cannot be applied in situ for rapid determination of pollution levels. ${ }^{11,12}$

Researchers have proved that laser induced breakdown spectroscopy (LIBS) is a competitive spectroscopy technology based on plasma spectral analysis from samples. When the laser ablated and excited the sample surface, the plasma created from the sample contains elemental information about the sample by the optical emission..$^{13,14}$ LIBS can measure various substances, including solid, liquid, colloid, and gas phases, and provides a nondestructive, rapid and in situ, simultaneous multi-elemental analysis. As a result, LIBS has been applied successfully to rapid on-site analysis of soil, food, art, and explosives. ${ }^{15,16}$ LIBS has the advantages of simple sample preparation, fast monitoring, simultaneous detection of multiple elements, and high sensitivity, making it ideal for in situ monitoring of multiple heavy metals in soils. ${ }^{17,18}$ Researchers have already conducted many studies on the detection of heavy metals in soils using conventional LIBS. ${ }^{19-21}$ For example, LIBS combined with RBF neural network used to analyze Cd in soils, and obtained the LOD of Cd was $16.5 \mathrm{mg}$ $\mathrm{kg}^{-1}{ }^{22}$ The spectral characteristics of Cd were analyzed by LIBS in pellet soil samples, yielding the calculated detection limits were $1.3,3.6$ and $4.0 \mu \mathrm{g} \mathrm{g}^{-1}$ for Cd II $214.441 \mathrm{~nm}, \mathrm{Cd}$ II $226.502 \mathrm{~nm}$ and Cd I $228.802 \mathrm{~nm}$, respectively. ${ }^{23}$ More recently, 
researchers have used LIBS combined with new technologies to improve soil heavy metal detection capabilities. In particular, the detection sensitivity of $\mathrm{Cu}$ and $\mathrm{Ag}$ in soils was improved by using microwave-assisted LIBS technology, whereby the detection limits of these two elements were lowered to $30 \mathrm{mg} \mathrm{kg}^{-1}$ and $23.3 \mathrm{mg} \mathrm{kg}{ }^{-1}$, respectively. ${ }^{24}$ LIBS has also been combined with laser-induced fluorescence technology could detect the limits of Cd elements in soils was 0.3 $\mu \mathrm{g} \mathrm{g}^{-1} \cdot{ }^{25}$ In addition, soil heavy metal $\mathrm{Pb}$ were detected using dual-pulse LIBS and spatial confinement, reducing the detection limits of $\mathrm{Pb}$ respectively to $20 \mathrm{mg} \mathrm{kg}^{-1}$, and $10 \mathrm{mg}$ $\mathrm{kg}^{-1} \cdot{ }^{26,27}$ However, the control standard of Cd in soils is below $0.2 \mathrm{mg} \mathrm{kg}^{-1}$ in China, while the sensitivity of above methods cannot reach this concentration. Furthermore, there are several problems with these methods: pre-treatment processes, such as grinding and drying, are still required; soils are prone to splatter during measurement; and these low detection limits are difficult to achieve in practice.

The ion-exchange resin can enrich heavy metals and commonly used to remove heavy metals from wastewaters..$^{28-30}$ In this paper, we tried to improve the sensitivity convenience of common LIBS system by combing ion-exchange resin with spatial confinement. We will demonstrate the following advantages of the method: (1) the sensitivity of LIBS will be enhanced by both spatial confinement and the enrichment of ion-exchange resin, which meets the requirement for the detection of cadmium in soils; (2) the complex pretreatment processes will be simplified through transfer cadmium from the soils into the ion-exchange resin; (3) the splash problems that troubles soil measurement using LIBS will be avoided.

\section{Materials and methods}

\subsection{Materials}

We collected the soil samples from field. Then we send them to Beijing Research Center for Agriculture Standards and Testing for testing. The results showed that there were no $\mathrm{Cd}$ in soils. The $\left(\mathrm{Cd}\left(\mathrm{NO}_{3}\right)_{2}\right)$ solution with concentration of $100 \mu \mathrm{g} \mathrm{ml}{ }^{-1}$ were prepared using the analytically grade (>99.99\%) solid powder of $\left(\mathrm{Cd}\left(\mathrm{NO}_{3}\right)_{2}\right)$. The cation exchange resin ECS60 was obtained from Hangzhou Yongzhou Water Treatment Technology Co., Ltd. The properties of the resins are shown in Table 1. The spatial confining device was a V-shaped stainless-steel plate having a $60^{\circ}$ angle.

Table 1 Characteristics of ECS60 cation exchange resins

\begin{tabular}{|c|c|}
\hline Characteristics & Values \\
\hline Active group & $-\mathrm{CH}_{2} \mathrm{~N}-\left(\mathrm{CH}_{2} \mathrm{COONa}\right)_{2}$ \\
\hline Matrix & Macroporous styrene-divinylbenzene \\
\hline Ionic forms as shipped & $\mathrm{Na}^{+}$ \\
\hline Physical form & Spherical beads \\
\hline Mean particle size $(\mathrm{mm})$ & $0.315-1.25$ \\
\hline $\mathrm{pH}$ range & $6-11$ \\
\hline Total exchange capacity & $\geq 1$ meq. $\mathrm{L}^{-1}$ \\
\hline
\end{tabular}

\subsection{Instruments}

The LIBS system comprised a laser, a spectrometer, a motorcontrolled high-precision three-dimensional platform, and a digital signal delay generator. Fig. 1 shows the structure of the experimental system. The laser was a Q-switched Nd:YAG Laser System (Beamtech Optronics Ltd., Beijing, China) with wavelength $1064 \mathrm{~nm}$. The pulse width was 3-5 ns with the repetition frequency of $20 \mathrm{~Hz}$. The maximum energy output of the pulse was $200 \mathrm{~mJ}$ and the exit angle was within $1 \mathrm{mrad}$. The laser was collimated by focusing lens and focused on sample surface. The laser-induced plasma light signal was collected using an optical fiber and transmitted to the spectrometer (HR2000+; Ocean Optics Co., Largo, FL, USA). The spectral range of the spectrometer was from $200 \mathrm{~nm}$ to $1100 \mathrm{~nm}$. A high-precision three-dimensional platform controlled by a stepper motor performed precise 3D adjustments, measuring different positions of each sample. A digital signal delay generator was used to generate a trigger delay between spectrometer acquisition and the laser. The signal delay device, three-dimensional platform, and spectrometer were all controlled by the same computer.

In this experiment, the laser pulse energy was set to $160 \mathrm{~mJ}$, the spectral range of spectrometer was set to from $200 \mathrm{~nm}$ to $1000 \mathrm{~nm}$, and the integral time was set to $2 \mathrm{~ms}$. This study focused on the atomic emission peaks of $\mathrm{Cd}$. Before the experiment, a background spectrum was collected by the spectrometer, which was deducted from all subsequent measurements.

\subsection{Method}

The experimental method was divided into the following steps:

(1) Contaminated soil samples preparation. The soil samples were mixed with different volume of $\left(\mathrm{Cd}\left(\mathrm{NO}_{3}\right)_{2}\right)$ solution. We then stirred it evenly to prepare Cd contaminated soil samples. Finally, Cd contaminated soil samples were dried at room temperature.

(2) Traditional pellet soil preparation. To prepare a traditional tablet, the contaminated soil samples were compacted into a cylindrical pellet with $13 \mathrm{~mm}$ diameter using

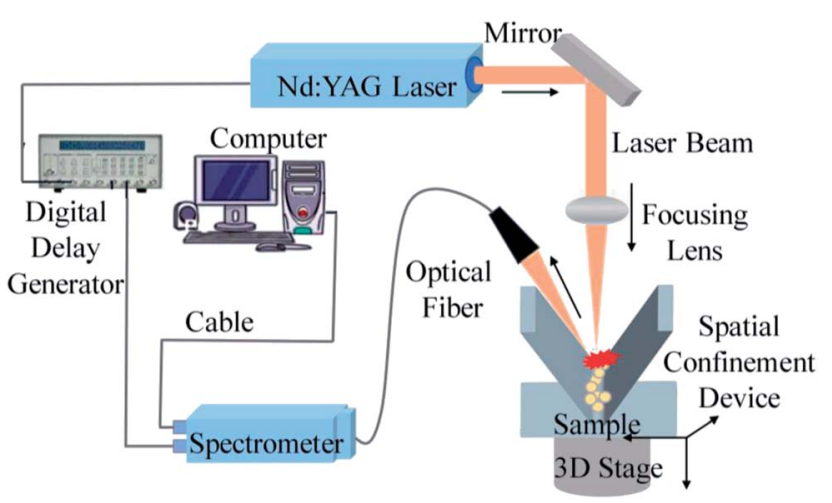

Fig. 1 The schematic diagram of the LIBS system. 
(a) Soil dissolution

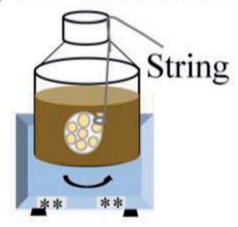

(c) Enriching

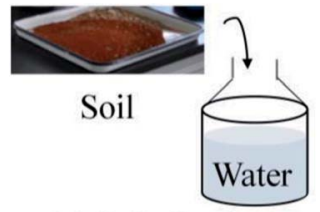

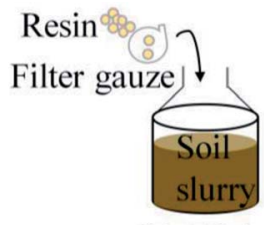

(b) Mixing

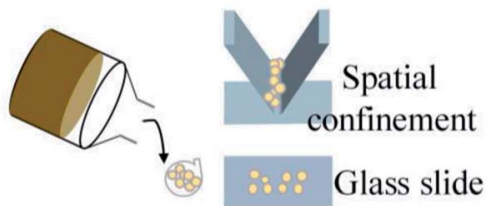

(d) Adhesion and drying
Fig. 2 The procedure of resin enrichment contains four steps (a) soil dissolution, (b) mixing, (c) enriching, (d) adhesion and drying.

a mechanical press (with $P=10 \mathrm{t}$ for $7 \mathrm{~s}$ ). The concentration of $\mathrm{Cd}$ in this soil ingot was $100 \mathrm{mg} \mathrm{kg}^{-1}$.

(3) Resin-enriched sample preparation. The resin enrichment sample preparation contains four steps, as shown in Fig. 2. First, the contaminated soil samples were remixed with deionized water, while water: soil ratio was $1: 1$. The concentration of the Cd elements in slurry were $0.667-13.33 \mathrm{mg} \mathrm{kg}{ }^{-1}$. Then we put resins into a filter gauze and mixed it with slurry by shaking in an oscillator. After the mixture for $150 \mathrm{~min}$ at a speed of $270 \mathrm{rpm},{ }^{31}$ we took the filter gauze out from the slurry. Next, we adhered resins on a glass substrate and a spatial confinement device, respectively. Finally, the samples were dried, measurements were carried out using the LIBS.

\section{Results and discussion}

\subsection{Resin enrichment and spatial confinement to enhance sensitivity}

To compare signal characteristics, samples prepared using the traditional tablet, resin enrichment coupled with spatial confinement method were measured using the LIBS system, with $\mathrm{Cd}$ concentration of $100 \mathrm{mg} \mathrm{kg}{ }^{-1}$ and $0.667 \mathrm{mg} \mathrm{kg}^{-1}$, respectively. In this experiment, the characteristic spectral peaks of Cd II occurred at $214.4 \mathrm{~nm}, 226.5 \mathrm{~nm}$ and Cd I was at $228.76 \mathrm{~nm}$, as shown in Fig. 3. It can be seen the spectral lines of Cd at $214.4 \mathrm{~nm}, 226.5 \mathrm{~nm}$ and $228.76 \mathrm{~nm}$ can be detected both by traditional tablet method (100 $\left.\mathrm{mg} \mathrm{kg} \mathrm{kg}^{-1}\right)$ and by resin enrichment coupled with spatial confinement $\left(0.667 \mathrm{mg} \mathrm{kg}^{-1}\right)$. However, Cd concentration in the pellet soil sample were 150 times higher than in the resin enrichment coupled with spatial confinement sample. Clearly, the resin enrichment coupled with spatial confinement method used in this study improved the detection capability of the LIBS technology obviously. This is because the resin matrix of styrene and the cross-linker divinylbenzene produce a polymerization reaction to form a long backbone structure with crosslinks. Given the matrix had a simple spectrum and $\mathrm{Cd}$ was enriched in the resin, the extraction and analysis of the spectral peaks of Cd was facilitated. Under confinement, the Cd signal strength also was

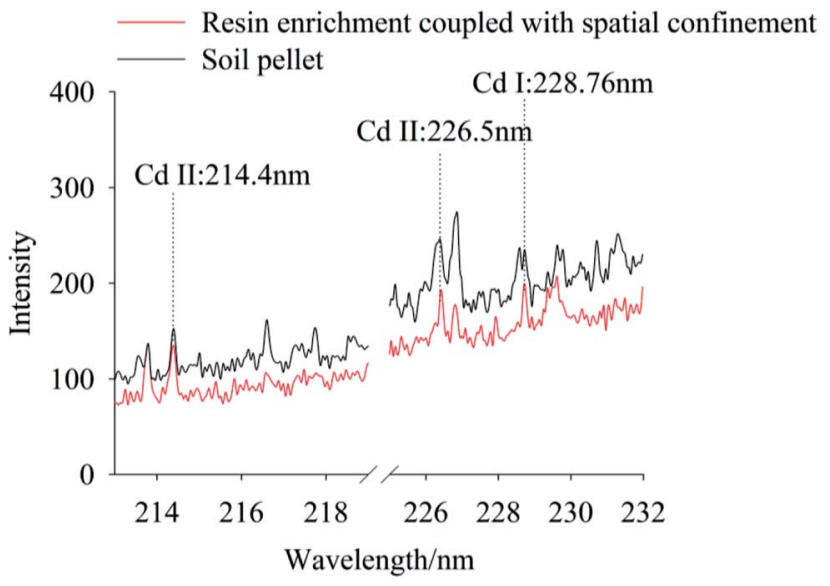

Fig. 3 The LIBS spectra of Cd polluted soil using the traditional pellet soil method and our method, while the $\mathrm{Cd}$ concentration is $100 \mathrm{mg}$ $\mathrm{kg}^{-1}$ for the former and $0.667 \mathrm{mg} \mathrm{kg}^{-1}$ for the latter. (To clearly show the differences among these spectra, we parallel moved each spectrum. The same operation were also taken in Fig. 4-8.)

enhanced. Compared with the traditional tablet method, these newer methods greatly simplified the pretreatment of the soil and avoiding contamination of the optical lens by soil splattered during analysis. In particular, the space confining device was simple to operate and required no structural modification of the instrument.

\subsection{The effect of spatial confinement in measurement}

The effect of resin enrichment coupled or not with spatial confinement on the characteristic peaks of $\mathrm{Cd}$ in soils were compared for Cd concentrations of $0.667 \mathrm{mg} \mathrm{kg}^{-1}$ and $6.67 \mathrm{mg}$ $\mathrm{kg}^{-1}$. Fig. 4 and 5 show the spectra of resin enrichment with and without spatial confinement. It should be noted that resin enrichment coupled with spatial confinement detected Cd II at $214.4 \mathrm{~nm}, 226.5 \mathrm{~nm}$ and Cd I at $228.76 \mathrm{~nm}$, showing obvious characteristic spectral peaks at both concentrations. When the Cd content was $0.667 \mathrm{mg} \mathrm{kg}^{-1}$, the resin enrichment without spatial confinement only detected a slight peak at $228.76 \mathrm{~nm}$,

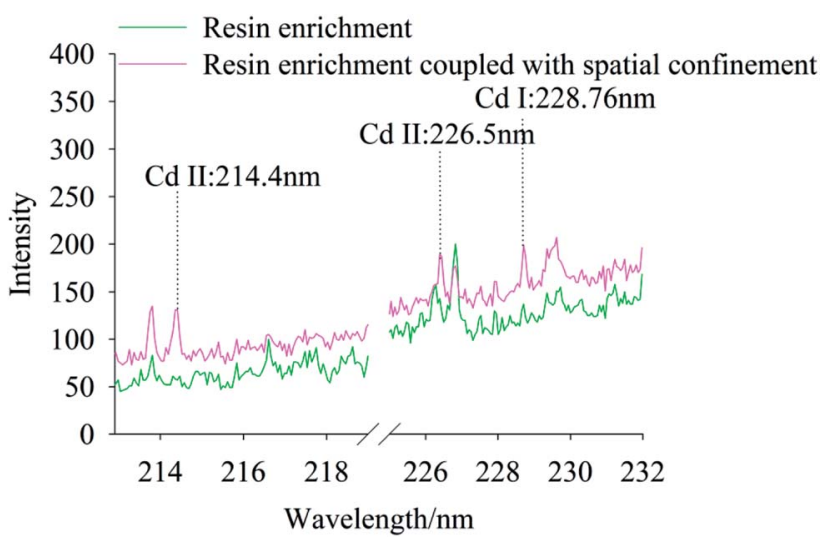

Fig. 4 The LIBS spectra of $\mathrm{Cd}$ polluted soil using resin enrichment method coupled with and without spatial confinement, while $\mathrm{Cd}$ concentration was $0.667 \mathrm{mg} \mathrm{kg}^{-1}$. 


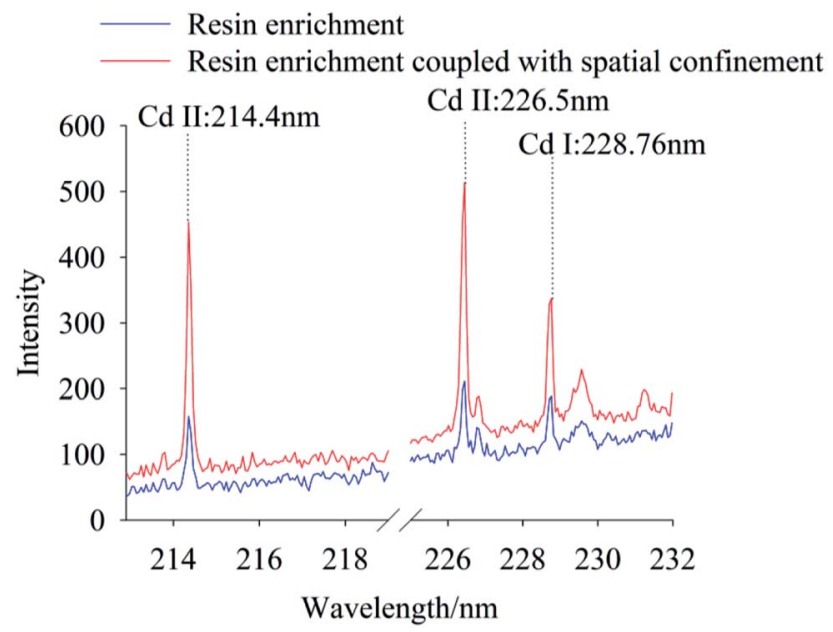

Fig. 5 The LIBS spectra of $\mathrm{Cd}$ polluted soil using resin enrichment method coupled with and without spatial confinement, while $\mathrm{Cd}$ concentration was $6.67 \mathrm{mg} \mathrm{kg}^{-1}$.

while peaks at $214.4 \mathrm{~nm}$ and $226.5 \mathrm{~nm}$ were not detected. When the Cd content was $6.67 \mathrm{mg} \mathrm{kg}^{-1}$, the emission lines of Cd were all significantly enhanced. This is because of the effects of spatial confinement of the laser plasma, which under the excited states enhanced binding effects, reflecting back the shock wave and compressing the plasmas plume, resulting in increased signal strength. ${ }^{32}$

\subsection{Quantitative measurement of heavy metals in soils}

To quantify different Cd contents in soils, samples were prepared for LIBS measurement using spatial confinement combined with resin enrichment with $\mathrm{Cd}$ contents ranging from $0.667 \mathrm{mg} \mathrm{kg}^{-1}$ to $13.33 \mathrm{mg} \mathrm{kg}^{-1}$. The characteristic spectral peaks of Cd at $214.4 \mathrm{~nm}, 226.5 \mathrm{~nm}, 228.76 \mathrm{~nm}$ are shown in Fig. 6-8, respectively. Obviously, as the concentration of $\mathrm{Cd}$ in soil samples increased, the intensity of the characteristic peaks of Cd also increased, reflecting the positive correlation between $\mathrm{Cd}$ concentration and signal intensity. Based on these results,

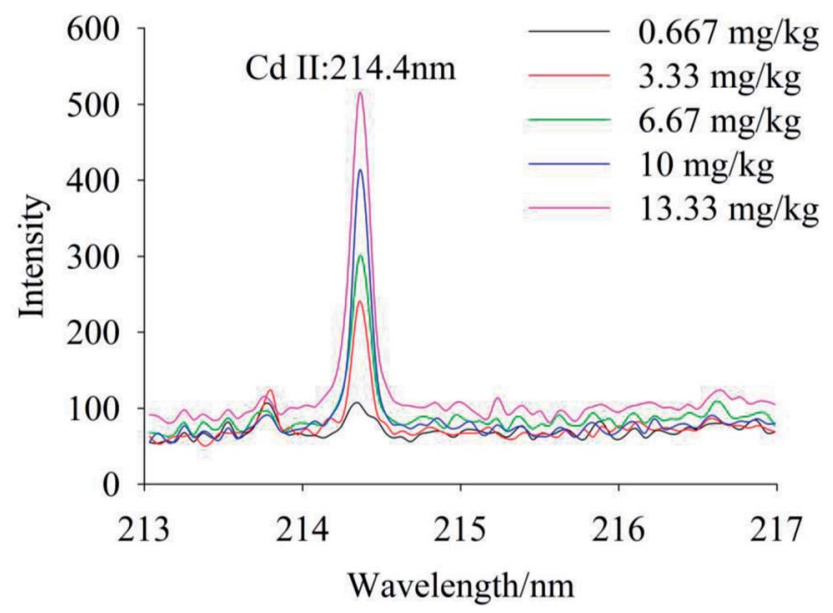

Fig. 6 The spectral peaks of $\mathrm{Cd}$ at $214.4 \mathrm{~nm}$, while $\mathrm{Cd}$ concentration was $0.667-13.33 \mathrm{mg} \mathrm{kg}^{-1}$.

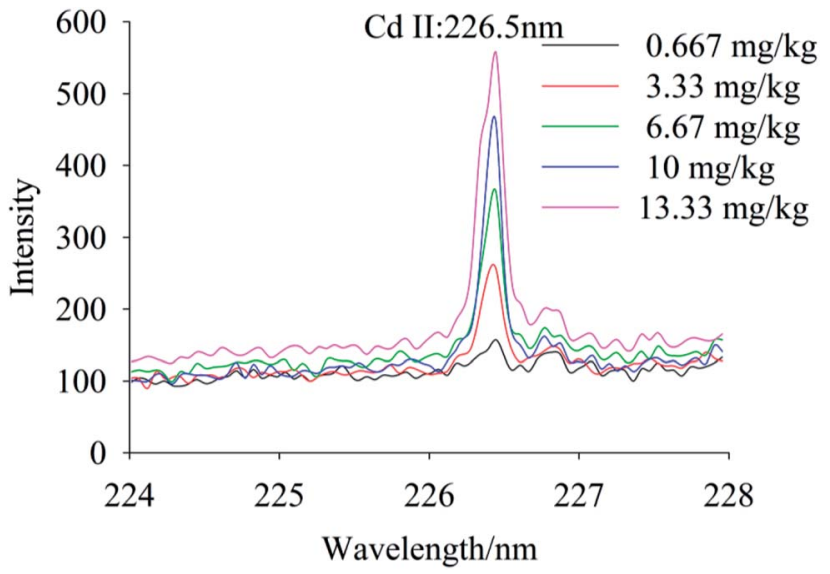

Fig. 7 The spectral peaks of $\mathrm{Cd}$ at $226.5 \mathrm{~nm}$, while $\mathrm{Cd}$ concentration was $0.667-13.33 \mathrm{mg} \mathrm{kg}^{-1}$.

we selected the Cd peak at $226.5 \mathrm{~nm}$ for quantitative analysis. A calibration curve was determined (Fig. 9), which indicates that Cd concentration in the soil had a linear relationship with characteristic peak intensity, with a coefficient of determination of 0.9715 .

\subsection{Limit of detection}

The limit of detection was $0.132 \mathrm{mg} \mathrm{kg}^{-1}$, which is determined by the ratio of the standard deviation of triplicate blank samples to the slope of the calibration curve. ${ }^{33}$ With the aid of high efficiency of absorption by resin and spatial confinement for plasmas plume, our method has largely improved the LOD for Cd, comparing with the conventional methods (which is $16.5 \mathrm{mg} \mathrm{kg}^{-1},{ }^{22} 3.6 \mu \mathrm{g} \mathrm{g}^{-1}$ (ref. 23) and $0.3 \mu \mathrm{g} \mathrm{g}^{-1},{ }^{25}$ respectively). The experiment results proved that the resin enrichment combined with spatial confinement method is much effective than the traditional table method. Our method satisfied the environmental quality standards of soil pollution $\left(0.2 \mathrm{mg} \mathrm{kg}^{-1}\right)$.

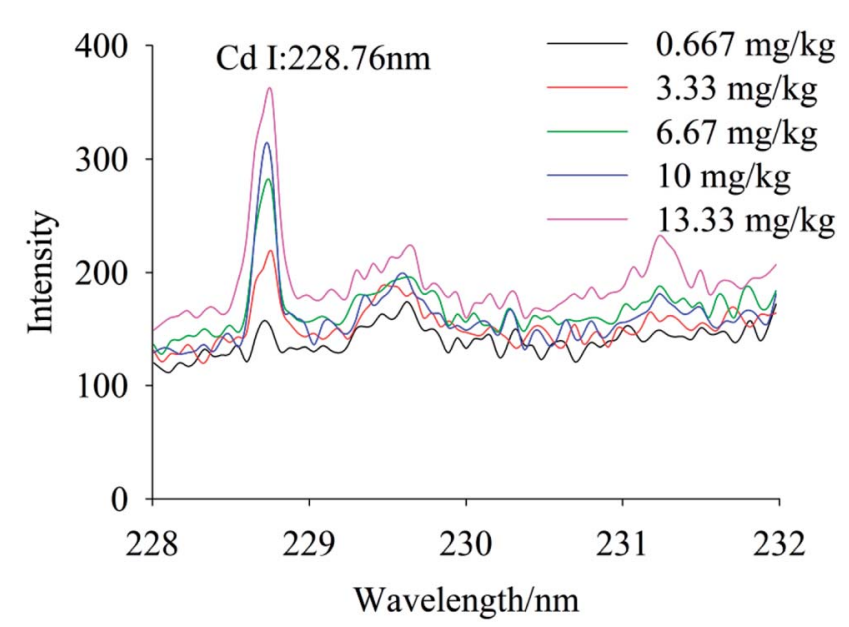

Fig. 8 The spectral peaks of $C d$ at $228.76 \mathrm{~nm}$, while $\mathrm{Cd}$ concentration was $0.667-13.33 \mathrm{mg} \mathrm{kg}^{-1}$. 


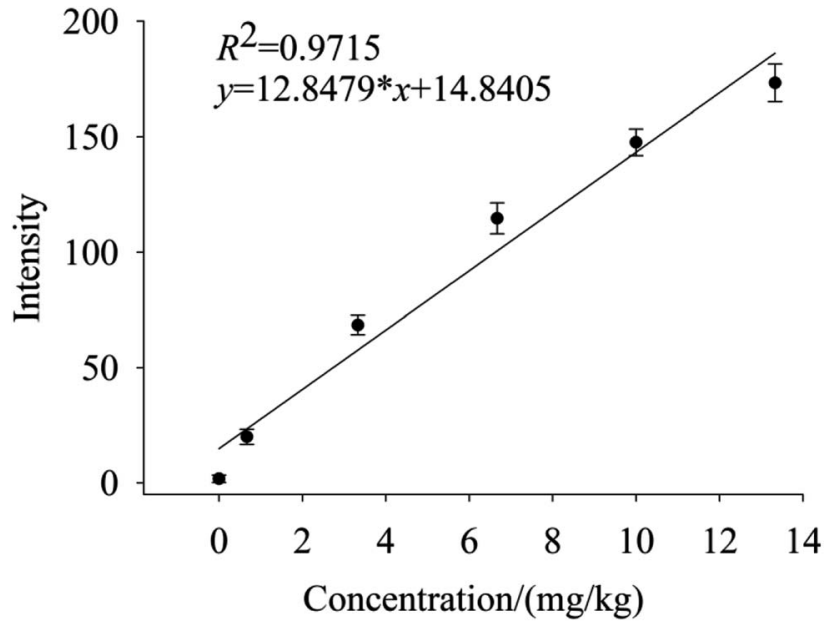

Fig. 9 Calibration curve of $\mathrm{Cd}$ at $226.5 \mathrm{~nm}$, while $\mathrm{Cd}$ concentration of $0-13.33 \mathrm{mg} \mathrm{kg}^{-1}$.

\section{Conclusion}

This experimental study demonstrated that LIBS measurements carried out on $\mathrm{Cd}$ in soil samples provided reliable quantitative results. Effects of the traditional tablet method, resin enrichment, and space confinement coupled with resin enrichment on the spectral characteristics of $\mathrm{Cd}$ peaks were analyzed. We conclude that: (1) compared with the resin enrichment method, spatial confinement coupled with the resin enrichment method markedly enhanced the signal of $\mathrm{Cd}$ from soil samples; (2) the resin enrichment method simplified pretreatment of samples and solved the problem of soil splash; and (3) the Cd II at $226.5 \mathrm{~nm}$ was selected for quantitative analysis, yielding a coefficient of determination of 0.9715 and a limit of detection of $0.132 \mathrm{mg} \mathrm{kg}^{-1}$. Heavy metals in soils can be divided into several forms-water-soluble metals, exchangeable metals, metals precipitated as inorganic compounds, metals complexed with large molecular-weight humic materials, metals adsorbed or occluded to precipitated hydrous oxides, metals precipitated as insoluble sulfide and metals bound within the crystalline lattice structure of primary minerals. Among them, water-soluble cadmium was the most mobile and plant available. The activities of exchangeable cadmium were much higher and its binding capacity with solid phase absorption medium was much weaker than others. The exchangeable cadmium was converted relatively easily to water-soluble cadmium. The watersoluble cadmium and exchangeable cadmium were the important source of cadmium contamination in soil, flora and fauna and could reflect soil pollution level in a way. ${ }^{34}$ Consequently, we used the resin to enrich these two forms of cadmium in soils and used LIBS to detect cadmium in our experiment. The results of this work provide a more accuracy method to detect trace heavy metals in soils using LIBS.

\section{Conflicts of interest}

There are no conflicts to declare.

\section{Acknowledgements}

This work was supported by National Key R\&D Program of China (2017YFD0801201-02), National Natural Science Foundation of China (31622040), Beijing Talents Fund (2016000021223ZK36) and Scientific and Technological Innovation Team of Beijing Academy of Agricultural and Forestry Sciences (JNKYT201604).

\section{References}

1 E. Frossard, W. E. H. Blum and B. P. Warkentin, Function of soils for human societies and the environment, Journal of Farm Economics, 2006, 37(5), 347-354.

$2 \mathrm{Z}$. Li, et al., A review of soil heavy metal pollution from mines in China: Pollution and health risk assessment, Sci. Total Environ., 2014, 468-469, 843-853.

3 V. W. De, P. F. Römkens and G. Schütze, Critical soil concentrations of cadmium, lead, and mercury in view of health effects on humans and animals, Rev. Environ. Contam. Toxicol., 2007, 191, 91.

4 M. Muchuweti, et al., Heavy metal content of vegetables irrigated with mixtures of wastewater and sewage sludge in Zimbabwe: Implications for human health, Agric., Ecosyst. Environ., 2006, 112(1), 41-48.

5 R. K. Rattan, et al., Long-term impact of irrigation with sewage effluents on heavy metal content in soils, crops and groundwater-a case study, Agric., Ecosyst. Environ., 2005, 109(3), 310-322.

6 M. F. Reis, et al., Human exposure to heavy metals in the vicinity of Portuguese solid waste incinerators-Part 1: biomonitoring of $\mathrm{Pb}, \mathrm{Cd}$ and $\mathrm{Hg}$ in blood of the general population, Int. J. Hyg. Environ. Health, 2007, 210(3), 455459.

7 S. Melaku, R. Dams and L. Moens, Determination of trace elements in agricultural soil samples by inductively coupled plasma-mass spectrometry: Microwave acid digestion versus aqua regia extraction, Anal. Chim. Acta, 2005, 543(1), 117-123.

8 L. Prioteasa, M. Prodana and M. Buzoianu, ICP-MS Determination of Some Metals and Metalloids Concentrations in Soil from Agricultural and Inhabited Areas of Romania, Rev. Chim., 2016, 67(7), 1314-1317.

9 T. Radu and D. Diamond, Comparison of soil pollution concentrations determined using AAS and portable XRF techniques, J. Hazard. Mater., 2009, 171(1-3), 1168-1171.

10 F. L. Pantuzzo, J. C. Silva and V. S. Ciminelli, A fast and accurate microwave-assisted digestion method for arsenic determination in complex mining residues by flame atomic absorption spectrometry, J. Hazard. Mater., 2009, 168(2), 1636-1638.

11 M. Soylak, Solid Phase Extraction of $\mathrm{Cu}(\mathrm{II}), \mathrm{Pb}(\mathrm{II}), \mathrm{Fe}(\mathrm{III})$, Co(II), and $\operatorname{Cr}(\mathrm{III})$ on Chelex-100 Column Prior to Their Flame Atomic Absorption Spectrometric Determinations, Anal. Lett., 2004, 37(6), 1203-1217.

12 M. Soylak, et al., Utilization of membrane filtration for preconcentration and determination of $\mathrm{Cu}(\mathrm{II})$ and $\mathrm{Pb}(\mathrm{II})$ in 
food, water and geological samples by atomic absorption spectrometry, Food Chem. Toxicol., 2010, 48(2), 517-521.

13 D. A. Cremers and L. J. Radziemski, Handbook of laserinduced breakdown spectroscopy, 2006.

14 D. W. Hahn and N. Omenetto, Laser-induced breakdown spectroscopy (LIBS), part I: review of basic diagnostics and plasma-particle interactions: still-challenging issues within the analytical plasma community, Appl. Spectrosc., 2010, 64(12), 335-366.

15 W. B. Lee, et al., Recent Applications of Laser-Induced Breakdown Spectrometry: A Review of Material Approaches, Appl. Spectrosc. Rev., 2004, 39(1), 27-97.

16 A. W. Miziolek, V. Palleschi and I. Schechter, Laser-induced breakdown spectroscopy (LIBS) : fundamentals and applications, Crit. Rev. Anal. Chem., 2006, 27(4), 257-290.

17 F. Capitelli, et al., Determination of heavy metals in soils by Laser Induced Breakdown Spectroscopy, Geoderma, 2002, 106(1-2), 45-62.

18 J. Peng, et al., Challenging applications for multi-element analysis by laser-induced breakdown spectroscopy in agriculture: A review, TrAC, Trends Anal. Chem., 2016, 85, 260-272.

19 M. Corsi, et al., Double pulse, calibration-free laser-induced breakdown spectroscopy: A new technique for in situ standard-less analysis of polluted soils, Appl. Geochem., 2006, 21(5), 748-755.

20 G. Nicolodelli, et al., Signal enhancement in collinear double-pulse laser-induced breakdown spectroscopy applied to different soils, Spectrochim. Acta, Part B, 2015, 111, 23-29.

21 A. M. Popov, F. Colao and R. Fantoni, Spatial confinement of laser-induced plasma to enhance LIBS sensitivity for trace elements determination in soils, J. Anal. At. Spectrom., 2010, 25(6), 2491-2494.

22 Z. K. Zheng, et al., Research of Laser Induced Breakdown Spectroscopy for Detection of Trace Cd in Polluted Soil, Spectrosc. Spectral Anal., 2009, 29(12), 3383-3387.

23 D. Santos Jr, et al., Evaluation of laser induced breakdown spectroscopy for cadmium determination in soils, Spectrochim. Acta, Part B, 2009, 64(10), 1073-1078.
24 Y. Liu, et al., Improvement of the sensitivity for the measurement of copper concentrations in soil by microwave-assisted laser-induced breakdown spectroscopy, Spectrochim. Acta, Part B, 2012, 73(73), 89-92.

25 F. Hilbk-Kortenbruck, et al., Analysis of heavy metals in soils using laser-induced breakdown spectrometry combined with laser-induced fluorescence, Spectrochim. Acta, Part B, 2001, 56(6), 933-945.

26 V. S. Burakov, et al., Analysis of lead and sulfur in environmental samples by double pulse laser induced breakdown spectroscopy, Spectrochim. Acta, Part B, 2009, 64(2), 141-146.

27 H. Suyanto, et al., Practical soil analysis by laser induced breakdown spectroscopy employing subtarget supported micro mesh as a powder sample holder, Spectrochim. Acta, Part B, 2017, 137, 59-63.

28 L. Agouborde and R. Navia, Heavy metals retention capacity of a non-conventional sorbent developed from a mixture of industrial and agricultural wastes, J. Hazard. Mater., 2009, 167(1), 536-544.

$29 \mathrm{~F} . \mathrm{Fu}$ and Q. Wang, Removal of heavy metal ions from wastewaters: a review, J. Environ. Manage., 2011, 92(3), 407418.

30 E. Pehlivan and T. Altun, Ion-exchange of $\mathrm{Pb}^{2+}, \mathrm{Cu}^{2+}, \mathrm{Zn}^{2+}$, $\mathrm{Cd}^{2+}$, and $\mathrm{Ni}^{2+}$ ions from aqueous solution by Lewatit CNP 80, J. Hazard. Mater., 2007, 140(1-2), 299-307.

31 S. Rengaraj, K. H. Yeon and S. H. Moon, Removal of chromium from water and wastewater by ion exchange resins, J. Hazard. Mater., 2001, 87(1), 273-287.

32 L. B. Guo, et al., Accuracy improvement of quantitative analysis by spatial confinement in laser-induced breakdown spectroscopy, Opt. Express, 2013, 21(15), 1818818195.

33 M. Safaeian, D. Solomon and P. E. Castle, Limits of detection in spectroscopy, Spectroscopy, 2003, 18(12), 112-114.

34 R. P. Gambrell, Trace and Toxic Metals in Wetlands - A Review, J. Environ. Qual., 1994, 23(5), 883-891. 